\title{
Associação entre o fator neurotrófico derivado do encéfalo (BDNF) e o transtorno depressivo: uma revisão de literatura
}

\author{
Association between brain-derived neurotrophic factor (BDNF) and depressive disorder: a
} literature review

Asociación entre el factor neurotrófico derivado del encéfalo (BDNF) y el trastorno depresivo: una revisión de la literatura

Thayná Bertolini dos Santos ORCID: https://orcid.org/0000-0002-9767-2334 Centro Universitário São Lucas, Brasil

E-mail: thaynareiche@outlook.com

Vytor Hugo Staut de Souza

ORCID: https://orcid.org/0000-0003-2019-7907 Centro Universitário São Lucas, Brasil E-mail: vytors11@hotmail.com

Noéli Cristina Gouveia Lopes

ORCID: https://orcid.org/0000-0001-8869-4104 Centro Universitário São Lucas, Brasil E-mail: noeligouvea@hotmail.com

Flávia Albuquerque Ferreira

ORCID: https://orcid.org/0000-0003-1562-9330 Centro Universitário São Lucas, Brasil

E-mail: flavialbuquerque_@hotmail.com

Cleber Queiroz Leite

ORCID: https://orcid.org/0000-0002-7847-1166 Centro Universitário São Lucas, Brasil E-mail: cleberqueiroz05@hotmail.com

Messias Genézio Santana da Silva

ORCID: https://orcid.org/0000-0002-8199-5374 Centro Universitário São Lucas, Brasil E-mail: messias.g.santana@gmail.com

Brian França dos Santos

ORCID: https://orcid.org/0000-0003-1574-630X

Universidade Iguaçu, Brasil

E-mail: drbrianfranca@hotmail.com

\section{Resumo}

Objetivos: O presente trabalho teve por objetivo, reunir e sistematizar os principais estudos disponíveis, que esclarecessem a íntima relação entre os níveis de Fator Neurotrófico Derivado do Encéfalo (BDNF) com o transtorno depressivo. Metodologia: Foram selecionados 30 trabalhos relacionados com o BDNF e transtorno depressivo de plataformas intexadoras, publicadod entre os anos de 2017 - 2021, sendo que, o foco foram artigos que apresentassem contribuições para o tema associando as duas condições. Resultados e Discussão: Diversos trabalhos que relacionam o BDNF ao transtorno depressivo demonstram uma relação entre níveis diminuídos desse polipeptídeo em pacientes com a patologia quando comparado com indivíduos saudáveis, servindo mesmo como biomarcador da doença, ademais, houve aumento dos níveis do citado fator quando realizados os tratamentso específicos para a depressão. Outros autores relacionam o aumento dos níveis do BDNF com a realização de atividades físicas e restrição calórica e aventam a possibilidade de tal atividade ser considerada como tratamento adjuvante ao convencional. Por fim, outros trabalhos se detêm nas alterações genéticas e epigenéticas rastreáveis através de análise genômica podem interferir na expressão do BDNF e servir como fatores de risco aumentado para desenvolvimento de desordens neuropsiquiátricas. Conclusão: Há evidêcias suficientes para embasar a fala de que o BDNF está relacionado e pode ser uma ferramenta promissora para o diagnóstico e futuras abordagens da patologia, porém são necessários novos estudos para consolidar os achados já demonstrados anteriormente, bem como determinar os níveis de BDNF a serem considerados como preditores de doença.

Palavras-chave: Fator neurotrófico derivado do encéfalo; Transtorno depressivo; Plasticidade neuronal; Antidepressivos. 


\begin{abstract}
Objectives: This study aimed to gather and systematize the main available studies, which would clarify the close relationship between the levels of Brain Derived Neurotrophic Factor (BDNF) with depressive disorder. Methodology: 30 articles related to BDNF and depressive disorder from indexing platforms, published between 2017 and 2021 , were selected, and the focus was on articles that presented contributions to the theme by associating the two conditions. Results and Discussion: Several studies linking BDNF to depressive disorder demonstrate a relationship between decreased levels of this polypeptide in patients with the pathology when compared to healthy individuals, even serving as a biomarker of the disease, in addition, there was an increase in the levels of this factor when performed specific treatments for depression. Other authors relate the increase in BDNF levels with the performance of physical activities and caloric restriction and suggest the possibility of such activity being considered as an adjuvant treatment to the conventional one. Finally, other studies focus on genetic and epigenetic alterations traceable through genomic analysis that can interfere with BDNF expression and serve as increased risk factors for the development of neuropsychiatric disorders. Conclusion: There is enough evidence to support the statement that BDNF is related and may be a promising tool for the diagnosis and future approaches to the pathology, but further studies are needed to consolidate the findings already demonstrated above, as well as to determine the levels of BDNF to be considered as predictors of disease.
\end{abstract}

Keywords: Brain-derived neurotrophic factor; Depressive disorder; Neuronal plasticity; Antidepressive agents.

\title{
Resumen
}

Objetivos: Este trabajo tuvo como objetivo recopilar y sistematizar los principales estudios disponibles en el área de la salud y que evidencian la estrecha relación entre los niveles de Factor Neurotrófico Derivado del Cerebro (BDNF) con el trastorno depresivo. Metodología: Se seleccionaron 30 artículos relacionados con el BDNF y el trastorno depresivo de plataformas de indexación, publicados entre 2017 y 2021, y el foco estuvo en los artículos que presentaban contribuciones al tema asociando las dos condiciones. Resultados y Discusión: Varios estudios que relacionan el BDNF con el trastorno depresivo demuestran una relación entre la disminución de los niveles de este polipéptido en pacientes con la patología, en comparación con individuos sanos, sirviendo incluso como biomarcador de la enfermedad. Además, se percibe un aumento en los niveles de este factor cuando se realizan tratamientos específicos para la depresión. Otros autores relacionan el aumento de los niveles de BDNF con la realización de actividades físicas y restricción calórica y sugieren la posibilidad de que dicha actividad sea considerada como un tratamiento adyuvante al convencional. Finalmente, otros estudios se centran en alteraciones genéticas y epigenéticas rastreables a través del análisis genómico que pueden interferir con la expresión de BDNF y operar como factores de riesgo incrementados para el desarrollo de trastornos neuropsiquiátricos. Conclusión: Existe evidencia suficiente para apoyar la afirmación de que el BDNF está relacionado y puede ser una herramienta prometedora para el diagnóstico y tratamiento del trastorno depresivo. Sin embargo, continuar el camino de la investigación permitirá consolidar los hallazgos realizados y referidos en este trabajo destacando que la determinación de los niveles de BDNF resultan relevantes al momento de considerar los eventuales predictores del trastorno depresivo.

Palabras clave: Factor neurotrófico derivado del encéfalo; Trastorno depresivo; Plasticidad neuronal; Antidepresivos.

\section{Introdução}

O Fator Neurotrófico Derivado do Encéfalo, ou ainda Fator Neurotrófico Derivado do Cérebro (BDNF - Brain-derived neurotrophic factor), é um polipeptídeo que faz parte da família das neurotrofinas, juntamente com o fator de crescimento do nervo (NGF - Nerve Growth Factor), neurotrofina-3, neurotrofina-4, dentre outros. Tais peptídeos atuam no tecido cerebral com importante contribuição para o crescimento, manutenção e sobrevivência neuronal, ademais, desempenham funções no aprendizado, memória e neuroplasticidade (Mizoguchi, Yao, Imamura, Hashimoto \& Monji, 2020).

O BDNF é produzido pelo tecido nervoso, tanto central como periférico, principalmente em áreas ligadas às emoções, humor e cognição, tais como córtex cerebral, hipocampo e amigdala (Chiou \& Huang, 2019) (Capibaribe, 2018). Além do tecido nervoso, ele pode ser originado em outros tecidos, a saber, o fígado, endotélio vascular e músculo liso (Chiou \& Huang, 2019). Essa produção pode ser afetada, tanto com aumento ou diminuição, a depender de estímulos, como os exercícios físicos resistidos, aprendizagem e estresse (Colaço, 2018).

A forma madura do BDNF é um polipeptídeo (13-kDa), que é originada a partir de uma proteína percursora chamada pró-BDNF ( 32-kDa). Essa, por sua vez, é produzida no retículo endoplasmático intracelular e pode seguir por algumas vias diferentes, sendo clivado em BDNF maduro ou BDNF pró-peptídio ( 17-kDa) (Chiou \& Huang, 2019). Essa clivagem pode ocorrer tanto no retículo endoplasmático (intracelular) ou por proteases, tais como a plasmina, ativador de plasminogênio tecidual ou metaloproteases no extracelular (Mizoguchi et al., 2020). Por fim, outra via possível é a excreção pelo retículo endoplasmático 
do próprio pró-BDNF, que vai agir em seu receptor sem ser clivado (Chiou \& Huang, 2019).

Quanto à ligação desses peptídeos aos seus respectivos receptores, o BDNF maduro possui afinidade com o receptor do tipo tirosina cinase B (TrkB) e as outras neurotrofinas se ligam a outros receptores dessa mesma classe, já em relação ao próBDNF, ele possui afinidade ao receptor p75, que pertence à família de moléculas transmembrana e também é receptor de citocinas, como o fator de necrose tumoral (TNF- $\alpha$ ) (Capibaribe, 2018).

A partir do momento em que se ligam aos seus respectivos receptores, o conjunto BDNF-TrkB e pró-BDNF-p75, produzem ações opostas no tecido nervoso do organismo, sendo que o conjunto BDNF maduro-TrkB é responsável, dentre outras coisas, pela estimulação do crescimento dendrítico, potencialização da capacidade sináptica, manutenção, crescimento e sobrevivência neuronal. Já o conjunto pró-BDNF-p75 faz estímulo à apoptose celular, atenuação da transmissão sináptica e supressão do crescimento dendrítico. É necessário que haja um equilíbrio entre as ações desses dois sistemas para que ocorra uma potencialização da plasticidade sináptica (Capibaribe, 2018) (Sartori, 2010).

Dito isso, nota-se a importância da função do BDNF para a fisiopatologia de vária doenças neurológicas, sendo que, estudos realizados na última década vêm propondo relações entre a expressão do BDNF e patologias como a esquizofrenia, transtorno bipolar e depressivo (Capibaribe, 2018) (Colaço, 2018).

Em se tratando de depressão, o Brasil pode ser classificado como o país mais deprimido de toda a América do Sul, e ocupa o segundo lugar no ranking de todo o continente americano, perdendo apenas para os Estados Unidos da América. São confirmados até o segundo semestre de 2017, 11.548 .577 casos, o que corresponde a 5,8\% da população brasileira. (World Health Organization, 2017). Nesse contexto, observa-se que a depressão tem impacto significativo não só no individuo, mas também no mundo, sendo, assim, identificada pelo Ministério da Saúde, como o mal do século (Pastori, 2020).

O transtorno depressivo é composto por oito subtipos, segundo o Manual diagnóstico e estatístico de transtornos metais (DSM-V), sendo o transtorno depressivo maior a condição clássica desse grupo de transtornos. A patologia caracteriza-se por episódios distintos com duração mínima de duas semanas, onde envolve alterações no afeto, cognição, funções neurovegetativas ou remissões interepisódicas. O diagnóstico pode ser baseado em episódio único, embora seja frequente haver recorrência nesse transtorno. Cabe ressaltar, ainda, a direta relação dos episódios de depressão maior e a possibilidade de comportamento suicida (Associação Psiquiátrica Americana, 2014).

De acordo com os critérios diagnósticos do transtorno depressivo maior, segundo o DSM-V, para confirmar o diagnóstico é necessário que dentre os sintomas haja, obrigatoriamente, humor depressivo ou perda de interesse ou prazer por pelo menos duas semanas, além dos demais sintomas relacionados como alterações psicomotoras e distúrbio do sono, redução no grau de concentração, alteração do peso corporal e perda de energia (Guerra \& Mesquita, 2020)

Ao observar a fisiopatologia do transtorno depressivo é possível verificar redução no sistema de monoaminas, o qual representa um grupo de neurotransmissores composto por serotonina, dopamina, noradrenalina, entre outros. De modo que, a depressão maior relaciona-se com danos na via de sinalização que coordena a neuroplasticidade, sobrevivência celular, diminuição no número e tamanho das células nervosas no hipocampo. Além disso, correlaciona-se com alteração no sistema endócrino, mais precisamente na redução de fatores do crescimento, principalmente o BDNF, o qual pode estar envolvido na gênese da depressão (Perito \& Fortunato, 2012).

As neurotrofinas, são proteínas capazes de estimular a diferenciação e sobrevivência dos neurônios, assim como promover atividade na modulação de transmissão e plasticidade sináptica. Nesse contexto, o BDNF tem experimentado importante relação com a atividade sináptica e de plasticidade, uma vez que o estresse crônico reduz a expressão do BDNF e inibe a fosforilação da proteína ligante ao elemento de resposta ao cAMP (CREB), sendo que a diminuição de seus níveis relaciona-se com a gravidade da depressão (Perito \& Fortunato, 2012).

O CREB, é responsável por promover a transcrição de éxons e genes que proporcionem resistência celular evitando o 
efeito anti-apoptótico. Já o BDNF, ativa uma cascata de sinalização para transdução de sinais, que podem liberar e ativar receptores neurotróficos. Assim, com a exposição ao estresse crônico ocorre diminuição dos seus níveis, além dos níveis de outras neurotrofinas, os quais reduzem a neurogênese, formação dendrítica e aumenta a vulnerabilidade celular (Perito \& Fortunato, 2012).

Tal fator tem significado, pois a relação entre o CREB e BDNF pode contribuir com novas perspectivas relacionadas aos medicamentos antidepressivos. Uma vez que, a ativação do CREB aumenta a expressão do BDNF e de proteínas antiapoptóticas, de modo que essa relação pode conferir ação farmacológica no sentindo de evitar a morte celular e aumentar a resistência a apoptose e, consequentemente, ser um alvo para terapia antidepressiva (Perito \& Fortunato, 2012).

Nesse contexto, o presente trabalho teve por objetivo, reunir e sistematizar os principais estudos primários, assim como abranger outras revisões literárias disponíveis, que esclarecessem a íntima relação entre os níveis de BDNF com o transtorno depressivo, bem como os diversos fatores que influenciam diretamente os níveis desse polipeptídeo no organismo, tais como a prática de atividade física, outras doenças neuropsiquiátricas, alterações genéticas e epigenéticas, estresse, dentre outros.

\section{Metodologia}

O trabalho em questão se trada de uma revisão integrativa e descritiva da literatura, a abordagem usada foi qualitativa, onde buscou-se as associações descritas na literatura, entre o Fator Neurotrófico Derivado do Encéfalo e o transtorno depressivo, objetivando sumarizar os pontos relevantes nessa temática.

Consoante a Ritter, Allonço e Lima (2021), trabalhos descritivos trazem por função descrever resultados a partir da busca de dados relacionados ao objetivo do trabalho. Dessa forma, deve-se buscar atingir uma descrição clara e representativa ao leitor, sobre a visão dos pesquisadores, ao que se relaciona à associação descrita na literatura entre o BDNF e o transtorno depressivo.

Para a elaboração do método do presente, utilizou-se a recomendação PRISMA como base de metodologia. Essa recomendação se trata de um checklist com 27 itens e 4 etapas, que, quando seguidos, servem para auxiliar os pesquisadores e autores a aprimorar o relato de revisões sistemáticas e meta-análises, trazendo os conceitos que são importantes na elaboração de qualquer trabalho científico (Galvão, Pansan, \& Harrad, 2015).

Seguindo o supracitado checklist, ressalta-se os critérios de elegibilidade para os trabalhos que compuseram a base de pesquisa para essa revisão, sendo: trabalhos publicados e finalizados, com acesso gratuito, que tenham sido publicados nos últimos 5 anos (2017-2021), redigidos em língua portuguesa, inglesa ou espanhola e que se relacionem com a temática aqui proposta.

As fontes utilizadas para a busca de tais trabalhos incluíram as plataformas indexadoras LILACS, Scientific Electronic Library Online (SciELO) e PubMed, sendo que as buscas se deram no mês de julho do ano de 2021.

Para a pesquisa dos trabalhos, foram utilizados os descritores "Depressive Disorder" or "Depression" and "BrainDerived Neurotrophic Factor", nas plataformas citadas acima.

Após a aplicação dos filtros de busca, foram encontrados 738 trabalhos relacionados com os descritores pesquisados. Desses, 715 eram indexados pela plataforma PubMed, 8 pela plataforma SciELO e 15 pela plataforma LILACS. Todos os trabalhos foram analisados pelos autores quanto ao seu conteúdo, a fim de selecionar os que pudessem contribuir para o tema proposto na pesquisa presente.

Em seguida à supracitada análise, 30 trabalhos foram selecionados para compor a base de pesquisa desse artigo, 28 da plataforma PubMed, 1 da plataforma SciELO e 1 da plataforma LILACS. Todo o processo de seleção dos trabalhos é demonstrado na Figura 1, a seguir. 
Figura 1: Fluxo de seleção dos relatos a partir das buscas nas plataformas indexadoras.

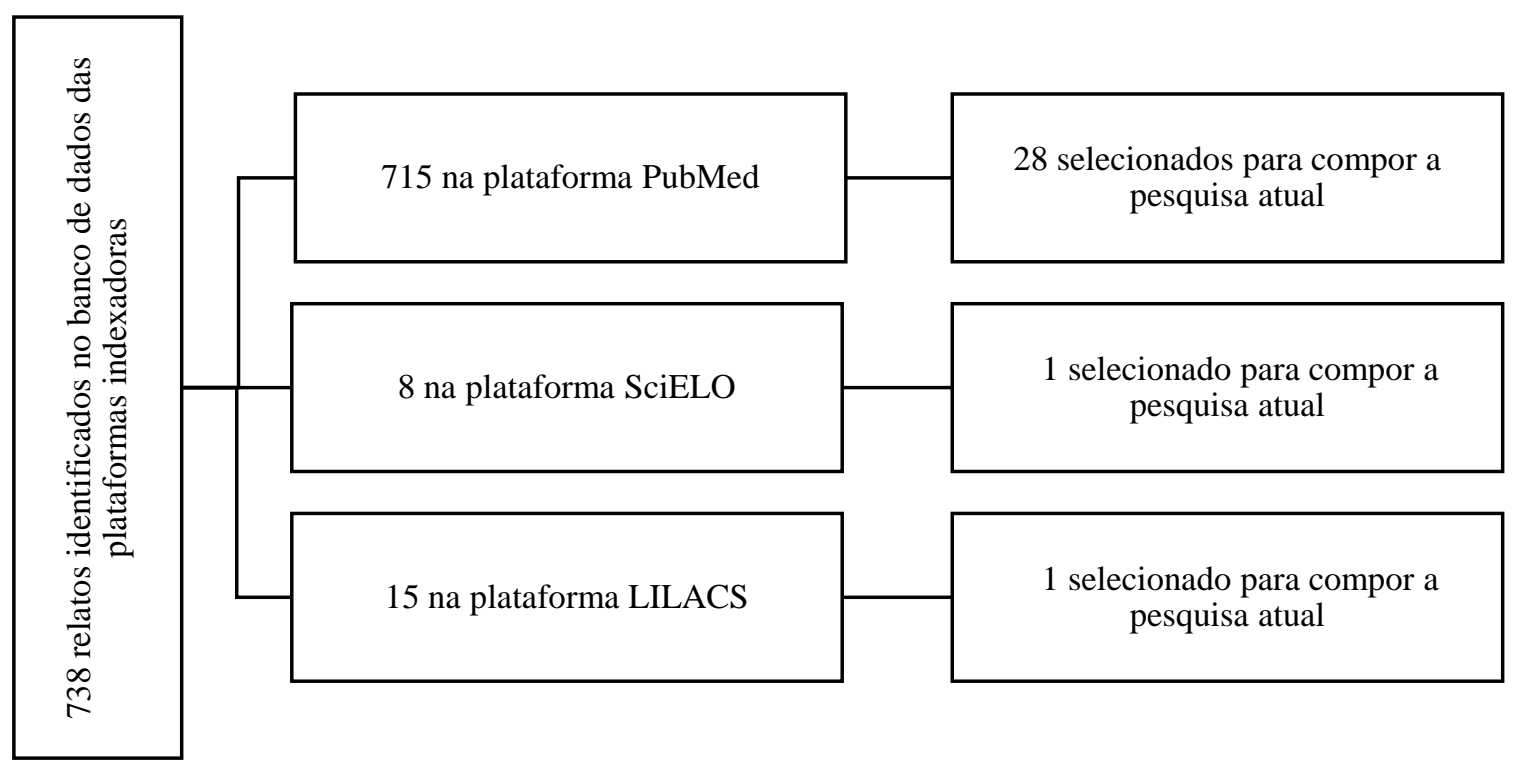

Fonte: Autores (2021).

\section{Resultados}

Entre os artigos selecionados, 03 foram publicados no ano de 2017, 05 no ano de 2018, 09 no ano de 2019, 08 no ano de 2020 e 05 no ano de 2021.

Os artigos foram dispostos abaixo na Tabela 1, onde são enfatizadas suas principais variáveis, tais como título, objetivos e conclusões atingidas.

Tabela 1. Detalhamento dos estudos selecionados.

\begin{tabular}{|c|c|c|}
\hline TÍTULO DO ARTIGO & OBJETIVO & CONCLUSÃO \\
\hline $\begin{array}{l}\text { Blood brain-derived } \\
\text { neurotrophic factor (BDNF) } \\
\text { and major depression: do we } \\
\text { have a translational } \\
\text { perspective? }\end{array}$ & $\begin{array}{l}\text { O estudo fez uma revisão } \\
\text { bibliográfica, a fim de determinar a } \\
\text { influência do fator neurotrófico derivado } \\
\text { do cérebro no sangue, relacionado ao } \\
\text { mecanismo patológico do transtorno } \\
\text { depressivo maior. }\end{array}$ & $\begin{array}{l}\text { Resultados empíricos já indicavam uma } \\
\text { associação entre o aumento da expressão gênica do BDNF e } \\
\text { a concentração periférica com o aumento da plasticidade } \\
\text { neuronal e neurogênese. Meta-análises também já } \\
\text { demonstraram a eficácia do uso de antidepressivo e a terapia } \\
\text { eletroconvulsiva na elevação dos níveis de BNDF no sangue. }\end{array}$ \\
\hline $\begin{array}{l}\text { The role of BDNF on } \\
\text { neural plasticity in depression }\end{array}$ & $\begin{array}{l}\text { Esta revisão destaca a relevância } \\
\text { da plasticidade neural mediada por fatores } \\
\text { neurotróficos e da fisiopatologia da } \\
\text { depressão. }\end{array}$ & $\begin{array}{l}\text { Um grande número de estudos mostrou que os } \\
\text { fatores neurotróficos, especialmente o BDNF, apresentam } \\
\text { estreita relação com a depressão. E alterações de fatores } \\
\text { neurotróficos funcionais podem resultar na fisiopatologia da } \\
\text { depressão por seu mecanismo de atenuação da plasticidade } \\
\text { neural. }\end{array}$ \\
\hline
\end{tabular}


Antidepressant drugs and physical activity: a possible synergism in the treatment of major depression?
$\mathrm{O}$ artigo mostrou uma visão geral sobre o possível sinergismo entre atividade física e antidepressivos no Transtorno Depressivo Maior (TDM).

\section{Physical exercise increased brain-derived neurotrophic factor in elderly population with depression}

Plasma BDNF concentrations and the antidepressant effects of six ketamine infusions in unipolar and bipolar depression

Plasma brain-

derived neurotrophic factor (BDNF) concentration and the BDNF Val66Met polymorphism in suicide: a prospective study in patients with depressive disorder

Alterations in serum

BDNF and gdnf levels after 12 weeks of antidepressant treatment in female outpatients with major depressive disorder.

Low serum brainderived neurotrophic factor is associated with suicidal ideation in major depressive disorder.

Low BDNF levels in serum are associated with cognitive impairments in medication-naïve patients with current depressive episode in BD II and MDD.
Este estudo objetivou avaliar o papel do exercício físico no efeito dos níveis de BDNF em idosos com depressão.

Este estudo teve finalidade de determinar a correlação das concentrações plasmáticas de BDNF (pBDNF) e a eficácia antidepressiva da cetamina.

Foi investigada a relação entre as concentrações de fator neurotrófico derivado do cérebro, um polimorfismo do $B D N F(196 \mathrm{G}>\mathrm{A})$ e a resposta a inibidores seletivos da recaptação da serotonina (SSRIs) entre pacientes chineses com transtorno depressivo maior (TDM).

Foram avaliados os níveis séricos de BDNF e GDNF antes e após 12 semanas de tratamento com antidepressivos em pacientes ambulatoriais com TDM.

\section{O estudo avalia os níveis} séricos de BDNF em indivíduos divididos em grupos de controles saudáveis, transtorno depressivo maior que não expressam ideação suicida e que expressam ideação suicida, sendo não medicados por pelo menos 6 semanas.

$\mathrm{O}$ estudo teve como princípio, investigar a função do BDNF na clínica e nos resultados cognitivos em pacientes sem tratamento prévio com transtorno depressivo maior (TDM) e transtorno bipolar II (TB II).

\section{Selective depletion of CREB in serotonergic neurons affects the upregulation of brain-derived neurotrophic factor evoked by chronic fluoxetine treatment.}

\section{Brain-derived} neurotrophic factor and major depressive disorder: evidence from meta-analyses.
A obra teve como premissa investigar alterações moleculares na expressão de neurotrofinas em camundongos, Creb1 TPH2CreERT2, após tratamento crônico com fluoxetina, bem como avaliar regiões cerebrais implicadas na depressão com inervação serotoninérgica profunda.

$\mathrm{Na}$ presente mini revisão, foi explorado a associação entre o BDNF, o polimorfismo do Val66Met e o transtorno depressivo maior (TDM), assim como os seus níveis após utilização de antidepressivos e eletroconvulsoterapia.
A atividade física estimula a neurogênese e a plasticidade sináptica, por meio da síntese e liberação de BDNF. Este é responsável por induzir alterações fisiológicas nos níveis de endorfina e monoaminas, aumentar a concentração plasmática de TGF- $\beta 1$ e reduzir os níveis de cortisol; também pode atuar como um "fator antiinflamatório" aumentando os níveis de IL-10 e suprimindo a produção de TNF- $\alpha$, além de exercer "efeitos semelhantes aos antidepressivos". O exercício também mostrou-se capaz de atuar nos principais sintomas da depressão, diminuindo a tristeza, a anedonia e os distúrbios do sono, ademais melhora o controle metabólico e as funções cognitivas, bem como reduz o risco de depressão e desenvolvimento de demência.

O percentual crescente do nível de BDNF mostrou-se maior em idosos depressivos que praticam exercícios físicos. O exercício físico pode ser benéfico no apoio à terapia de idosos com depressão.

Este estudo preliminar, sugere que as concentrações basais de pBDNF parecem estar correlacionadas com a eficácia antidepressiva da cetamina em pacientes chineses com depressão.

As concentrações de BDNF foram
significativamente menores em pacientes com tentativa / ideação de suicídio. As concentrações de BDNF podem servir como um marcador de resposta para o tratamento com antidepressivos em TDM.

O presente estudo, sugere que os níveis séricos de BDNF e GDNF basais são mais elevados do que os níveis pós-tratamento em alguns pacientes ambulatoriais de TDM leve a moderado. Ademais, a alteração significativa no nível de BDNF e GDNF após o tratamento foi observada em pacientes com remissão do quadro.

Em síntese, o artigo apresenta uma nova relação da hipertrofia neuronal por fatores neurotróficos, assim como uma nova hipótese sobre os níveis de BDNF como marcador periférico associado a ideação suicida dentro do transtorno depressivo maior, o qual propõe explorar posteriormente a neurobiologia para compreender tal mecanismo.

Foi demonstrado a diminuição do BDNF sérico em paciente com TDM e TBII, sugerindo que o fator neurotrófico pode estar envolvido na fisiopatologia dos dois transtornos, e ainda que tanto o BDNF, quanto déficits cognitivos, são de baixa eficiência em distinguir depressão e bipolaridade. Além disso, sugere que amostras maiores e longitudinais para estudos finais de acompanhamento são necessárias para explorar futuramente esse tópico.

Observou regulação positiva do BDNF no hipocampo ou córtex pré-frontal, após o uso da fluoxetina, por serem dependentes do CREB em neurônios exclusivamente serotoninérgicos. Dessa forma, então, propõe explorar futuramente novas hipóteses da regulação do CREB, nos neurônios serotoninérgicos relacionado à manutenção da ação de drogas antidepressivas pela regulagem do BDNF.

O BDNF é o biomarcador melhor compreendido para o estado de transtorno depressivo maior e sua resposta ao tratamento, apesar de não ter havido relação entre o polimorfismo Val66Met do gene BDNF com o TDM ou o volume hipocampal. No entanto, os níveis de plasma/soro de BDNF foram reduzidos em pacientes com TDM agudo em comparação com controles saudáveis, além disso, tanto o tratamento com antidepressivos, quanto a 


\begin{abstract}
Brain-derived neurotrophic factor precursor in the hippocampus regulates both depressive and anxietylike behaviors in rats.
\end{abstract}

Meta-analyses of
comparative efficacy of
antidepressant medications on
peripheral BDNF
concentration in patients with
depression.

Accuracy of brainderived neurotrophic factor levels for differentiating between Taiwanese patients with major depressive disorder or schizophrenia and healthy controls.

Serum brain-derived neurotrophic factors in taiwanese patients with drugnaïve first-episode major depressive disorder: effects of antidepressants.

The diagnostic value of the combination of serum brain-derived neurotrophic factor and insulin-like growth factor-1 for major depressive disorder diagnosis and treatment efficacy

BDNF genetic variants and methylation: effects on cognition in major depressive disorder

Neurotrophic factor BDNF, physiological functions and therapeutic potential in depression,

neurodegeneration and brain cancer

\footnotetext{
$\begin{array}{ccc}\text { Reduced } & \text { serum } \\ \text { BDNF levels are } & \text { associated }\end{array}$ with the increased risk for developing MDD: a casecontrol study with or without antidepressant therapy

Changes in

Hippocampal Plasticity in Depression and Therapeutic Approaches Influencing These Changes
}

$\mathrm{O}$ artigo teve como ponto norteador, investigar o papel do próBDNF no hipocampo de ratos com fenótipo semelhante com de depressão ou ansiedade, fazendo uso ainda da injeção intra-hipocampal de anticorpo antiproBDNF, neutralizador do pró-BDNF.

\section{A meta-análise visa revisar os} diferentes efeitos dos medicamentos antidepressivos nos níveis periféricos de BDNF relacionado ao transtorno depressivo maior, e fazer recomendações futuras para pesquisas.

\section{$\mathrm{O}$ artigo busca avaliar, com} precisão, os níveis do BDNF entre pacientes com transtorno depressivo maior, esquizofrenia e controle saudáveis, visto que há associação da psicopatologia desses eventos, mas estudos nesse sentido são raros.

O presente estudo, por um
período de 6 anos, examinou o nível sérico de BDNF em pacientes com transtorno depressivo maior, sem uso de fármacos, e os comparou com controles saudáveis de acordo com o sexo. Além disso, avaliou a relação do BDNF, comportamento suicida e depressão, de acordo com escala de Hamilton, antes e depois do tratamento com antidepressivo.

Objetivou avaliar a relação entre o BDNF e o IGF-1 com a depressão, bem como analisar se tais fatores podem ser usados, juntos ou separados, como biomarcadores para o transtorno depressivo.

Analisar a associação entre as variações genéticas e epigenéticas do BDNF, com o desempenho neurocognitivo, de pacientes portadores de transtorno depressivo em comparação com pacientes saudáveis.

Examinar o conhecimento disponível sobre o BDNF e os mecanismos de sinalização a ele relacionados, analisar os efeitos antidepressivos do BDNF relacionados com a plasticidade neuronal e ressaltar a função do BDNF na neuroproteção, bem como na patogênese dos gliomas cerebrais.

Avaliar o BDNF sérico em pacientes com transtorno depressivo, com e sem tratamento, e comparar com pessoas saudáveis.

Introduzir as várias alterações na plasticidade da região hipocampal na depressão, assim como discutir qual o papel do BDNF e da restrição calórica no tratamento da depressão. eletroconvulsoterapia aumentaram os níveis séricos de BDNF em pacientes com TDM.

Observou-se, que em ambos os modelos o proBDNF aumenta no hipocampo e a injeção antiproBDNF melhorou o quadro de depressão e da ansiedade no comportamento dos ratos. Sugerindo, dessa forma, que apesar de existir fatores comportamentais e morfológicos distintos entre as duas comorbidades, o proBDNF é um mediador comum para regular os dois transtornos.

Há indício de aumento dos níveis periféricos do BDNF com o uso de antidepressivos e, ainda que antidepressivos distintos induzam diferentes níveis de BDNF, ressalta-se a sertralina, que tem efeito singular na concentração de BDNF em um período curto de tempo. Entretanto, ensaios confirmatórios são necessários para as observações feitas pelo estudo.

O estudo apoiou a premissa de que o BDNF tem precisão moderada na distinção de homens com transtorno depressivo maior e mulheres com esquizofrenia, quando comparados com os controles saudáveis. De modo que, sugeriram amostras maiores no futuro para confirmar ainda mais os resultados.

Observou que os níveis de BDNF em pacientes com transtorno depressivo maior (TDM), que nunca fizeram uso de fármacos, foi menor quando comparado com os controles saudáveis, bem como pacientes com TDM, com tratamento prévio, foram mais propensos a responder. Os resultados quanto a ação da droga e a fisiopatologia da depressão permanece sem desfecho adequadamente estabelecido, necessitando novas pesquisas para comprovar resultados futuramente.

Concluiu-se que, o BDNF está diminuído em pessoas com depressão e o IGF-1 aumentado. Ademais, esses fatores separadamente são bons biomarcadores para o transtorno depressivo, porém, quando unidos, são um excelente biomarcador.

$\mathrm{O}$ estudo conclui que a metilação do gene promotor do BDNF, juntamente com interações com fatores moduladores, pode influenciar no desempenho cognitivo o paciente.

O BDNF se monstra como uma das moléculas promissoras para o melhor entendimento da etiologia da depressão relacionada a transmissão sináptica, bem como demonstra relação com a neuroproteção e neuroplasticidade e, mais recentemente, parece estar envolvido na patogênese e desenvolvimento de tumores cerebrais.

O nível sérico reduzido de BDNF pode estar envolvido na fisiopatologia do transtorno depressivo, e esses níveis baixos podem ser usados como um marcador de risco para a depressão maior.

O BDNF desempenha um papel central na neuroplasticidade hipocampal e uma variedade de alterações envolvem a ativação ou inibição das vias de sinalização do mesmo. A restrição calórica mostra benefícios em uma variedade de doenças neurológicas, 


\begin{tabular}{l}
\hline \multicolumn{1}{c}{ BDNF } \\
$\begin{array}{l}\text { overexpression in } \\
\text { hippocampus the ventral } \\
\text { promotes } \\
\text { antidepressant- }\end{array}$ \\
$\begin{array}{l}\text { anxiolytic-like } \\
\text { and }\end{array}$ \\
$\begin{array}{l}\text { activity in } \\
\text { knockonin }\end{array}$ \\
\hline \multicolumn{2}{c}{ transportert of exercise on } \\
major depressive disorder and \\
schizophrenia: a BDNF \\
focused approach
\end{tabular}

Relationship of brain-derived neurotrophic factor, malondialdehyde, and 8-Hydroxy 2-Deoxyguanosine with post-ischemic stroke depression

Differential

neuroinflammatory response in male and female mice: $a$ role for BDNF

\begin{tabular}{|c|}
\hline Brain-derived \\
\hline $\begin{array}{lr}\text { neurotrophic } & \text { factor, } \\
\text { depression, and physical } \\
\text { activity: making } \\
\text { neuroplastic connection }\end{array}$ \\
\hline \begin{tabular}{cc}
\multicolumn{2}{c}{ Brain-derived } \\
neurotrophic factor
\end{tabular} \\
\hline
\end{tabular}

\begin{tabular}{l}
\hline $\begin{array}{l}\text { Screening of brain- } \\
\text { derived neurotrophic factor }\end{array}$ \\
(BDNF) single nucleotide \\
polymorphisms and plasma \\
BDNF levels among Malaysian \\
major depressive disorder \\
patients
\end{tabular}

Association of BDNF VAL66MET polymorphism and brain bdnf levels with major depression and suicide

Interaction between polymorphisms in SLC6A4 and BDNF on major depressive disorder in a sample of the argentinean population

Brain-derived neurotrophic factor as a clinical biomarker in predicting the development of post-stroke depression: a review of evidence

incluindo a depressão, e pode ser usada como uma forma fisiológica de tratamento no futuro.

A superexpressão de BDNF modulada em laboratório, em ratos, mostrou um desfecho positivo, podendo ser um alvo terapêutico em estudos posteriores para a melhora dos sintomas depressivos. ventral do hipocampo de animais que apresentavam comportamentos semelhantes a depressão, além de uma baixa expressão de BDNF.

Revisar qual o efeito dos exercícios aeróbicos em pessoas que apresentam doenças neurológicas, tais como esquizofrenia e depressão enfatizando o papel do BDNF no aprendizado, memória e atenção.

Elucidar a correlação entre BNDF, melondialdeído (MDA) e 8hidroxi 2-desoxiguanosina (8-OhdG) nos casos de depressão com acidente vascular cerebral agudo (AVC agudo) tipo isquêmico.

Analisar a resposta, bem como
o impacto do BNDF e do sistema imunológico em camundongos machos e fêmeas tratados com lipopolissacarídeo indutor de citocina (LPS).

Analisar os níveis de BNDF nas principais regiões do cérebro e sua correlação com transtorno depressivo maior, assim como função da farmacoterapia.

Revisar resultados sobre níveis de BNDF e modificações epigenéticas na esquizofrenia, transtorno depressivo maior e transtorno bipolar.

Investigar e determinar a
associação de três variantes do BNDF (rs6265, rs1048218 e rs1048220) em pacientes com transtorno depressivo maior na Malásia.
Os exercícios aeróbicos causam diferentes respostas nos níveis de BDNF e em alguns estudos verificou-se melhora das funções cognitivas acompanhadas do aumento do BDNF, no entanto, novos estudos precisam ser aplicados para entender qual o papel do exercício no transtorno depressivo e esquizofrenia.

Os níveis de BNDF no soro está altamente relacionado com depressão no quadro agudo pós AVC isquêmico, os quais interligam-se com distúrbios de memória e neuropsiquiátricos.

O aumento da resposta inflamatória em camundongos machos foi independente do genótipo, enquanto que na fêmea foi predominante em genótipos heterozigotos, sugerindo correlação entre BNDF e o sexo.

Demonstrou-se que, níveis alterados de BNDF contribuí para o transtorno depressivo maior, enquanto que terapêuticas como antidepressivos e atividades físicas otimizam o BNDF para promover saúde neuronal.

BNDF se mostrou diferencialmente expresso em diversos transtornos psiquiátricos. A utilização de plantas medicinais usados em distúrbios do sono obteve correlação positiva com a atividade do BNDF.

O alelo BNDF rs6265 (A) presente, aumenta o risco de desenvolver transtorno depressivo maior (TDM) na população estudada, sugerindo relação entre BDNF e TDM.
Investigar a associação do polimorfismo Val66Met do BNDF com depressão, suicídio e adversidades no início da vida.

Analisar associação entre transtorno depressivo maior com BNDF, gene APOE e HTR2A em uma amostra da população argentina.

Revisar evidências já existentes sobre à mudança na expressão do BDNF em pacientes com depressão pós acidente vascular cerebral (AVC).
A diminuição do alelo Met aumentou o risco de depressão nos indivíduos, além disso, encontrou-se menores níveis de BNDF naqueles indivíduos expostos à adversidades no início da vida.

Sugeriu uma possível relação entre BDNF, APOE e neurotransmissão serotoninérgica na patogênese do transtorno depressivo maior.

Fonte: Autores (2021).

\section{Discussão}

O Fator Neurotrófico Derivado do Cérebro é de extrema importância para a sobrevivência e manutenção dos neurônios, estando intimamente envolvido com funções emocionais e cognitivas. Arosio, Guerini, Voshaar e Aprahamian (2021), realizou uma revisão bibliográfica, a fim de determinar a influência do BDNF no sangue, como mecanismo patológico relativo ao 
transtorno depressivo maior. Resultados empíricos já indicaram uma associação entre o aumento da expressão gênica do BDNF e a concentração periférica com o aumento da plasticidade neuronal e neurogênese. Meta-análises também já demonstraram a eficácia do uso de antidepressivo e a terapia eletroconvulsiva na elevação dos níveis de BNDF no sangue. Entretanto, embora as evidências tenham apontado para níveis aumentados de BDNF após a terapia antidepressiva, vários fatores, como resultados heterogêneos, tamanho de amostra reduzido, viés de publicação e diferentes medidas de BDNF (soro ou plasma), representam um desafio na interpretação da relação entre o BDNF no sangue periférico e transtorno depressivo maior (TDM).

O autor conclui que, a ausência de evidências científicas contundentes impede o uso na prática clínica do BNDF para diagnóstico e tratamento do transtorno depressivo, no entanto, deixa claro que estudos futuros com maiores amostras e melhores metodologias podem definir a concentração/alteração do BDNF como biomarcador da desordem depressiva, abrindo caminho para tratamentos específicos dessa patologia.

Phillips (2017), por sua vez, coletou dados e estudos demonstrando que a síntese do BDNF ocorre tanto no sistema nervoso central quanto no sistema nervoso periférico através de neurônios, e que há firme conexão da redução do mesmo no plasma de pacientes que cometeram suicídio ou que sofrem de transtorno depressivo maior. O mesmo relata que um estudo postmortem de pessoas com depressão revelou decréscimo na proteína BDNF no hipotálamo e no hipocampo, sendo eventualmente usado como biomarcador de depressão e comportamento suicida para aprimorar os diagnósticos e seguimentos psiquiátricos.

Nesse contexto, Emon et al. (2020), fez uso da curva característica de operação do receptor (ROC) para análise da possibilidade de uso do BDNF como um parâmetro diagnóstico ou preditivo de depressão, encontrando uma área sob a curva de 0.821 e sensibilidade, especificidade, valor preditivo positivo e valor preditivo negativo de $72,4 \%, 73,1 \%, 68,3 \%$ e $78,5 \%$ respectivamente, com um valor de corte de BDNF de $221.05 \mathrm{pg} / \mathrm{mL}$.

Do mesmo modo, em seu estudo, Troyan e Levada (2020), demonstraram que os valores de BDNF e IGF-1 eram relevantes para o diagnóstico ou predição de transtorno depressivo em pessoas sem tratamento, o que corrobora com Emon et al. (2020), em relação ao BDNF. Através da análise da curva ROC foi demonstrado área sob a curva de 0.840 para o BDNF, com sensibilidade de $81 \%$ e especificidade de $73 \%$ para um corte de $763.17 \mathrm{pg} / \mathrm{mL}$ e 0.824 para o IGF-1, com sensibilidade de $84 \%$ e especificidade de $64 \%$. Ademais, ressaltam que, quando combinados, os dois fatores mostram excelência para o diagnóstico do transtorno depressivo, com área sob a curva de 0.916 .

Estudos demonstraram que, o BDNF desempenha um papel importante na fisiopatologia de vários transtornos psiquiátricos e no mecanismo de ação de drogas psicotrópicas. Dados fornecem evidências diretas para apoiar a hipótese neurotrófica de depressão, que demonstrou diminuir a expressão de fatores neurotróficos em pacientes deprimidos, sendo que está pode ser revertida com tratamento antidepressivo eficaz. Por fim, conclui-se que alterações de fatores neurotróficos funcionais podem resultar na fisiopatologia da depressão, por seu mecanismo de atenuação da plasticidade neural, e um grande número de estudos evidencia que os fatores neurotróficos, especialmente o BDNF, apresentam uma estreita relação com a depressão.

O estresse e depressão crônica estão associados à redução da produção do BDNF, já o uso de medicamentos antidepressivos aumenta a quantidade deste no hipocampo, sendo que a administração de fluoxetina de forma crônica e dentro da faixa terapêutica em humanos, restabeleceu a plasticidade neuronal (Maya Vetencourt et al., 2008 citado por Phillips, 2017). Os dados acima descritos, confirmam o que diz Yang et al. (2020), que revisou uma recente literatura sobre o papel do BDNF na plasticidade neural da depressão. Tais resultados corroboram com Emon et al. (2020), em seu estudo, no qual houve a análise de 82 pacientes controle, comparados com pacientes diagnosticados com transtorno depressivo em tratamento (44 indivíduos) e ainda com pacientes diagnosticados com transtorno depressivo sem tratamento anterior (41 indivíduos) e revelou níveis diminuídos de BDNF em pacientes sem tratamento prévio, bem como que o tratamento com antidepressivos, tais como sertralina, paroxetina, venlafaxina, escitalopram e fluoxetina puderam causar aumento, tanto do nível de BDNF, quanto da neurogênese. 
Zhou et al. (2017), reafirma em seu estudo que o nível de BDNF sérico, à custa do nível do soro, após tratamento antidepressivo, com inibidores seletivo da recaptação de serotonina (SSRI) e inibidores da recaptação de serotonina e noradreanalina (SNRI), subiu consideravelmente em pacientes com transtorno depressivo maior, em curto período de tempo, cerca de 4-12 semanas.

Kishi, Yoshimura, Ikuta e Iwata (2018), mencionam a redução do volume hipocampal em indivíduos com transtorno depressivo maior, e que em indivíduos saudáveis, o volume do hipocampo é significativamente maior. Além disso, revelam que os níveis do BDNF no sangue decrescem significativamente no transtorno depressivo maior agudo, o que tem relação positiva com Chiou e Huang (2017), assim como relaciona-se com a afirmativa de Zhou et al. (2017), onde afirma que os níveis de BDNF do soro são significativamente alterados, mas o plasmático não, na presença de depressão. É mencionado ainda, em sua revisão de literatura, a eletroconvulsoterapia como farmacocinética para depressão resistente ao tratamento convencional, onde observou-se elevação dos níveis séricos, mas não plasmáticos de BDNF. Cita-se, dessa forma, a direta relação do uso de eletroconvulsoterapia e antidepressivos como fatores que aumentam os níveis séricos de BDNF no transtorno depressivo maior.

Não só Guerrera et al. (2020), como também Kurdi e Flora (2019), Colucci-D’Amato, Speranza e Volpicelli (2020) e Gökçe, Güneş e Nalçaci (2019), avaliaram a influência da atividade física na depressão. Guerrera, et al. 2020, fornece uma visão geral sobre o possível sinergismo entre atividade física e antidepressivos no TDM. A atividade física pode agir em conjunto com o tratamento antidepressivo ao resgatar a sinalização de neurotrofinas em pacientes com TDM, promover melhora da saúde neuronal e recuperação da função em circuitos relacionados ao transtorno, além de aumentar a resposta farmacoterapêutica.

A atividade física exerce efeitos benéficos no desenvolvimento cerebral pré e pós-natal, estimulando a neurogênese e a plasticidade sináptica, bem como faz aumentar a síntese e liberação de BDNF e reduz a hiperativação do eixo HPA, induzindo alterações fisiológicas nos níveis de endorfina e monoaminas, além de aumentar a concentração plasmática de TGF- $\beta 1$ e reduzir os níveis de cortisol.

Ademais, também pode atuar como um "fator anti-inflamatório" aumentando os níveis de IL-10 e suprimindo a produção de TNF- $\alpha$, e dessa forma, exerce efeitos semelhantes aos antidepressivos. A atividade física, do mesmo modo, se mostrou capaz de atuar nos principais sintomas da depressão, onde diminui a tristeza, a anedonia e os distúrbios do sono, tal qual melhorou o controle metabólico e as funções cognitivas, como atenção e concentração, também declinou o risco de depressão e desenvolvimento de demência.

Tais dados, falam a favor dos estudos de Colucci-D’Amato et al. (2020) e Gökçe et al. (2019). De maneira que, o primeiro relacionou exercícios aeróbios com o aumento dos níveis de BDNF e consequente aumento volumétrico de áreas cerebrais, tais como a região hipocampal. Já o segundo trabalho, traz em sua revisão, que a maior parte dos estudos relacionando os exercícios aeróbicos e BDNF remetem à uma associação positiva com aumento das neurotrofinas. Porém, há estudos que são controversos e com resultados sem demonstrar tal associação. Todavia, é descrito na revisão uma melhora na cognição, principalmente em atividades relacionadas à memória, em pessoas que praticam exercícios aeróbios, o que pode estar relacionado ao aumento do BDNF.

Kurdi e Flora (2019), em seu estudo avaliaram o papel do exercício físico no efeito dos níveis de BDNF em idosos com depressão. O estudo teve a participação de 35 mulheres idosas com episódios depressivos com base no (DSM-V), inscritas como grupo de tratamento, e 35 mulheres idosas sem episódios depressivos, inscritas como grupo de controle, e submetidas exercício físico em forma de esteira. Ficou evidenciado que, o exercício físico aumentou a produção de BDNF em ambos os grupos de idosos com e sem depressão, porém, o percentual crescente do nível de BDNF mostrou-se maior em idosos depressivos que praticam exercícios físicos, pois o mesmo reduz os níveis de glicose no sangue, fazendo com que a produção de corpos cetônicos do fígado aumente como compensação pela diminuição dos níveis de glicose no cérebro e mantem a estabilidade das fontes de energia para o mesmo. 
Outra categoria que mostrou-se eficaz no combate ao transtorno depressivo são às com gastos de energia e movimentos corporais gerados pelos músculos esqueléticos, também denominada "PA", sendo o exercício físico uma subcategoria da PA. Trabalho pré clínico demonstrado por Philips (2017), relatou que a PA crônica tem capacidade de otimizar os níveis centrais de BDNF, principalmente no hipocampo, sendo mais relevante na depressão induzida por estresse, pela ligação com vias neuro inflamatórias e de neuroplasticidade, devido à degradação do triptofano e ativação do receptor 5-HT. Exercício aeróbico crônico também aumenta os níveis de BDNF de forma periférica.

Alguns estudos paralelos, citados pelo mesmo autor, evidenciam que PA aumenta o BDNF mesmo em pacientes não medicados para transtorno depressivo maior, apesar de portador da doença, bem como eleva a eficácia do tratamento quando realizados antes da terapia farmacológica, indicando a importância do pré-tratamento com exercícios físicos para ampliar as chances de sucesso da terapia medicamentosa. Apesar do tratamento eficaz para o transtorno depressivo ainda ser um mistério, alguns métodos estão contribuindo para otimizar a terapêutica oferecida aos pacientes que sofrem deste mal.

Nesse sentido, outra análise feita por Teng et al. (2021), narrou a correlação entre os indivíduos com depressão que não usam antidepressivos, onde observaram baixos níveis de BDNF quando comparados com os controles saudáveis. Teng et al (2021), ainda, relata a hipótese de que os níveis baixos de BDNF, em grupos com depressão, podem estar relacionados à interrupção da homeostase do pro-BDNF, m-BDNF e BDNF, sendo, dessa forma, o nível de BDNF um gatilho para desordem psíquica, como a depressão, visto que danifica funções dos neurônios, consequentemente desencadeia problemas cognitivos, entre outros. Nesse contexto, o estudo apoia a hipótese de que o nível sérico de BDNF é um provável biomarcador de função cognitiva deteriorada e ressalta que o aumento deste, por meio de exercícios aeróbios, melhora a atrofia hipocampal e reduz a depressão.

Ademais, Zheng et al. (2021), em seu estudo, teve como objetivo determinar a correlação das concentrações plasmáticas de BDNF (pBDNF) e a eficácia antidepressiva da cetamina na depressão unipolar e bipolar. O método avaliou 94 indivíduos com depressão que receberam seis infusões intravenosas de cetamina, nessa conformidade, os resultados apresentaram uma melhora significativa nas pontuações da Escala de Avaliação de Depressão de Montgomery-Asberg (MADRS) e aumento das concentrações de pBDNF encontrada após completar seis infusões de cetamina, em comparação com a linha de base. Esse estudo preliminar sugeriu que as concentrações basais de pBDNF parecem estar correlacionadas com a eficácia antidepressiva da cetamina em pacientes com depressão.

Colucci-D'Amato et al. (2020), em seu trabalho de revisão, corroboram com os autores anteriormente citados em relação ao aumento do BDNF após o tratamento do transtorno depressivo, ressaltando que todas as classes medicamentosas interferem e estimulam a ativação do receptor TrkB, além de citarem que a cetamina pode causar alterações agudas com aumento do BDNF e dos receptores TrkB.

Outra revisão, realizada por Xu et al. (2020), reforça o pensamento relacionado à diminuição dos níveis de BDNF em pacientes portadores de depressão, bem como traz à tona as relações com a neuroplasticidade, que é diminuída em situações de queda do BDNF. Outrossim, adiciona que a restrição calórica pode demonstrar efeitos antidepressivos, devido a essa prática ser relacionada com uma menor morte neuronal na região hipocampal, assim como menor perda de material genético (DNA) nessa região e, sobretudo, redução dos níveis de leptina que, por ser considerado como um fator pro-inflamatório, pode se relacionar com a perda neuronal e depressão, sendo a restrição calórica fator protetor.

Por conseguinte, Ai et al. (2019), em seu estudo avaliou a relação entre as concentrações de Fator Neurotrófico Derivado do Cérebro, o polimorfismo do $B D N F$ (196G> A) e a resposta a inibidores seletivos da recaptação da serotonina (SSRIs), entre 125 pacientes e 91 controles saudáveis chineses, com transtorno depressivo maior (TDM). Na conclusão do estudo, observouse- a utilização de concentrações de BDNF como biomarcador para suicídio, sendo que a ideação suicida foi apoiada pela observação de concentrações de BDNF significativamente mais baixas em pacientes com tentativa de suicídio. 
Já Ferrer et al. (2019), em seu trabalho relacionado ao estudo da metilação genética de genes, relacionados a expressão do BDNF e o transtorno depressivo, após analisar 134 pessoas, sendo 64 diagnosticadas com transtorno depressivo e 70 pacientes saudáveis, demonstrou que houve associação entre a metilação de áreas do gene promotor do BDNF e a cognição, influenciado por sexo (sendo mais prevalente em mulheres), traumas prévios na infância e diagnóstico de transtorno depressivo. Ademais, sugere que tais metilações podem contribuir para déficits cognitivos observados em pacientes com transtorno depressivo.

Ainda sobre as alterações genéticas e epigenéticas do BDNF, Aldoghachi et al. (2019), realizou um estudo caso controle, com um total de 300 casos e 300 controles na Malásia, combinando pacientes recrutados de hospitais públicos e selecionados por idade e sexo, associado ao risco de suscetibilidade ao transtorno depressivo maior (TDM). O objetivo, dessa forma, de tal abordagem foi denominar a associação de três variantes do BDNF (rs6265, rs1048218 e rs1048220) com a patologia referida. Dentre os resultados, o mais expressivo indica que a variante mutante rs6265 aumenta a chance de desenvolver TDM em 2,05 vezes (IC 1,48-3,65) em comparação com o tipo selvagem.

O mesmo estudo, revelou que indivíduos com genótipo mutante obtiveram razão de chances de 1,7 (IC 95\% 1,17-2,47) de desenvolver TDM em comparação com outros genótipos, o que corrobora com outros estudos caso-controle realizado em outros países como China e Coreia. Rossetti et al. (2019), por sua vez, evidenciou o aumento da resposta inflamatória em camundongos fêmeas com genótipos heterozigotos, sugerindo associação entre BDNF dependente do sexo. Tais descobertas reforçaram a importância dos níveis de BDNF relacionados as chances de desenvolver TDM, ressaltando a necessidade de futuras pesquisas para polimorfismos dos nucleotídeos do gene BDNF.

Diniz et al. (2021), realizou estudo com ratos, nos quais gerou uma superexpressão de BDNF, demonstrando que os ratos tiveram uma melhora do comportamento anedônico, bem como efeito positivo nos transtornos do humor, não expressando influência significativa sobre a ansiedade. Tais conclusões, podem sugerir que humanos apresentem resultados parecidos, porém novos estudos são necessários para avaliar quais são os efeitos adversos que a superexpressão do BDNF pode causar.

Rafa-Zablocka, kreiner, Baginska e Nalepa (2018), em seu estudo, avaliou as neurotrofinas Creb1 de camundongos em tratamento crônico com fluoxetina e observou expressão intensamente aumentada de BDNF após 21 dias de tratamento, mas que essa condição se deve a íntima relação do BDNF com o CREB, visto que, após tratamento crônico com fluoxetina, houve aumento no hipocampo de CREB, que diretamente aumenta a expressão de BDNF. Além disso, o estudo ainda relata a interação entre essas duas neurotrofinas e o sistema serotoninérgico, onde regulam a plasticidade neural, o estímulo de estresse e consequentemente a eficácia de antidepressivos. Porém, devido a heterogenicidade da transmissão de serotonina essa interdependência não é de fato definida, uma vez que os níveis baixos de BDNF também contribuem para essa alteração nos receptores de serotonina, diminuindo a sua expressão.

Zhong et al. (2019), em seu estudo, avaliou a alteração cerebral de ratos com fenótipo semelhante a ansiedade e outros com fenótipo semelhante a depressão, o qual observou diminuição da complexidade de neurônios nos ratos com depressão comparados com o grupo controle, ou seja, há diminuição da complexidade dendrítica. Mas, surpreendentemente, ao avaliar o nível de BDNF nessas amostras, não foram observadas mudanças significativas, o que levou a sugerir que tanto depressão, quanto ansiedade tornam a regulação do pro-BDNF positiva no hipocampo.

Nesse sentido, para confirmar que o pro-BDNF se encontrava aumentado, no hipocampo dos ratos com fenótipo semelhante a depressão e outros semelhantes a ansiedade, aplicaram uma injeção intra-hipocampal bilateral de Ab-pro-BDNF monoclonal, o qual neutraliza o pro-BDNF. Observando, em seguida, que as injeções não alteraram o comportamento basal, mas que nos ratos com fenótipo semelhante aos de depressão, haviam diferentes expressões de pro-BDNF em regiões diferentes do cérebro, sendo que no núcleo accumbens ela se encontrou diminuída. Nesse contexto, o estudo, não foi conclusivo se a neutralização do pro-BDNF hipocampal inibe o comportamento depressivo ou mesmo o ansioso.

Syafrita, Amir, Susanti e Fadhilah (2020), realizaram um estudo observacional com 72 pacientes pós quadro de acidente 
vascular cerebral (AVC), tipo isquêmico, no Hospital Dr. M. Djamil na Indonésia, para observar os níveis de BDNF usando método ELISA e teste de Mann-Whitney. Dividiu-se em dois grupos: com e sem depressão, sendo evidenciado que os níveis de BDNF eram mais baixos no grupo com depressão comparados àqueles sem depressão. Tal resultado está de acordo com o trabalho realizado por Shan, Zheng e Froud (2021), no qual correlaciona os níveis baixos de BDNF e depressão pós AVC.

O acidente vascular cerebral isquêmico (AVCi) é o tipo mais comum de AVC, configurando 85\% de todos os casos. Há uma incidência elevada de sequelas e depressão pós AVC isquêmico, estando o mesmo fortemente associado à produção de espécies reativa de oxigênio (ROS) e espécies reativas de nitrogênio (RNS), as quais, segundo o estudo de Liu et al. (2017) citado por Syafrita et al. (2020), apoiado pelo estudo de Rybka et al. (2013) citado por Syafrita et al. (2020), desempenham um papel importante na patogênese da depressão, apontando o melondialdeído (MDA) como marcador preditivo de pós AVC, sendo este, formado pela reação oxidativa no tecido cerebral.

O dano oxidativo no DNA pode ser previsto pela elevação dos níveis de 8-hidroxi-2'-desoxiguanosina (8-OhdG) no tecido corporal, sangue ou urina; sua elevação associada a pacientes com depressão foi demonstrada pelo estudo de Black, Bot, Scheffer, Cuijpers e Penninx (2015) após quadro de AVC isquêmico (Black, et al., 2015 citado por Syafrita et al., 2020). O nível de Fator Neurotrófico Derivado do Cérebro, encontrado no soro, após quadros de acidente vascular encefálico, está diretamente correlacionado com distúrbios psiquiátricos e de memória.

Embora muitos estudos corroborem com a diminuição do BDNF em associação com o transtorno depressivo maior, outros demonstram resultados conflitantes. Em 2017, Chiou e Huang estudaram os níveis séricos de BDNF em 71 pacientes deprimidos e 71 pacientes controles saudáveis, os quais observaram baixos níveis séricos do Fator Neurotrófico Derivado do Cérebro, mas que a quantidade sérica desse fator, não dita a gravidade da depressão e, ainda, quando correlaciona o nível de BDNF após tratamento com antidepressivos em grupos com transtorno depressivo maior, esse valor não varia significativamente (Chiou \& Huang, 2017).

No entanto, foi relatado que mesmo com poucos estudos a época, os autores mencionaram a importância dos baixos níveis do Fator Neurotrófico Derivado do Cérebro em pacientes com o comportamento suicida, o qual desempenha associação relevante na fisiopatologia, visto que, foi demonstrado níveis ainda mais baixos da proteína BDNF sérica em indivíduos com tal comportamento. Além disso, de acordo com o estudo, foi observado, ainda, tendência de queda do nível de BDNF no sexo feminino com depressão, mas não no sexo masculino com depressão.

Desenvolvendo o que diz o estudo de Chiou e Huang (2017), é descrito uma íntima relação entre os níveis séricos de BDNF e depressão, acrescido ainda da interligação com a ideação suicida, segundo Khan et al. (2019). Em seu estudo, foram analisados os níveis do fator neurotrófico derivado do cérebro em 76 controles saudáveis e 68 indivíduos unipolares com transtorno depressivo maior (TDM), os quais foram subclassificados em TDM com e sem ideação suicida. Observou-se que, os níveis de BDNF no grupo com depressão, é menor ao comparar com os indivíduos que não possuem a comorbidade, assim como ao correlacionar dentre os que apresentam o transtorno de depressão, aqueles com ideação suicida possuem níveis ainda mais baixos de BDNF.

Contudo, ao relacionar quão menor é o nível de BDNF no grupo saudável com o grupo com depressão sem ideação suicida, percebeu-se que a diferença não é significativa entre eles. Dessa forma, Khan et al. (2019), ao longo de seu estudo, questiona a verdadeira relação do nível de BDNF com o transtorno depressivo e enfatiza sua maior dependência com o suicídio, visto que o grupo com depressão associado a ideação suicida teve valores de BDNF significativamente mais baixos comparados aos outros.

Somado a mesma perspectiva, o estudo de Teng et al. (2021) obteve relação semelhante ao de Khan et al. (2019) ao relacionar os níveis séricos de BDNF em 3 grupos, sendo eles: pacientes com transtorno bipolar II, transtorno depressivo maior e pacientes controles saudáveis. Avaliou-se que, os níveis séricos de BDNF são significativamente menores no grupo com 
transtorno bipolar II em comparação com o depressivo. Além disso, que os níveis do fator neurotrófico no grupo com transtorno depressivo também é inferior quando correlacionado com o grupo de controles saudáveis, porém não há diferença estatística relevante entre eles.

Chiou e Huang (2019) em seu estudo, analisaram três grupos, os quais são: transtorno depressivo maior, esquizofrenia e controles saudáveis, sendo respectivamente 273, 224 e 390 amostras no total. Seus resultados concordam com os estudos de Khan et al. (2019) e Teng et al. (2021), onde afirma diferença pouco significativa dos níveis de BDNF ao comparar transtorno depressivo maior com controles saudáveis, mas que, no entanto, ao relacionar esquizofrenia com controles saudáveis os níveis de BDNF caem significativamente. Ressalta-se, porém, que uma das limitações do estudo foi a dificuldade para dividir, com precisão, os grupos de pacientes de acordo com seus respectivos transtornos psíquicos, dada a possibilidade de sobreposição de transtornos e o fato de os diagnósticos serem eminentemente clínicos.

Por fim, Park e Lee (2018), avaliaram alterações nos níveis séricos de BDNF e GDNF, após 12 semanas de tratamento com antidepressivos, em 23 pacientes ambulatoriais, do sexo feminino, com transtorno depressivo maior, sendo que, nos resultados, 19 indivíduos (82,6\%), estavam em depressão leve a moderada. Todos os pacientes com TDM, tinham níveis séricos de BDNF e GDNF significativamente mais elevados, na linha de base, do que aqueles após 12 semanas de tratamento com antidepressivos. O presente estudo, sugere que os níveis séricos de BDNF e GDNF basais são mais altos do que os níveis póstratamento, em alguns pacientes ambulatoriais, de TDM leve a moderado, o que vai de encontro com diversos trabalhos supracitados, e a alteração significativa no nível de BDNF e GDNF, após o tratamento, foi observada apenas em pacientes com remissão.

\section{Conclusão}

O Fator Neurotrófico Derivado do Cérebro, é um polipeptídeo que é produzido, em sua maioria, nos tecidos nervosos centrais e periféricos, e está associado ao crescimento e manutenção neuronal, além de desempenhar funções no aprendizado, memória e neuroplasticidade, afetando aspectos emocionais e cognitivos do ser. Nesse sentido, diversos estudos recentes buscam associações entre tal fator e doenças neuropsiquiátricas recorrentes na atualidade, tal como a depressão.

No presente estudo, após a revisão de diversos artigos relacionados ao BDNF em associação com o transtorno depressivo, fica evidenciado que há relação entre os seus níveis e a patologia citada, de modo que o mesmo se encontra diminuído em associação com diversas doenças neuropsiquiátricas, dentre as quais, a depressão, onde há estreita relação, principalmente ao se somar às ideações suicidas.

Ademais, os níveis de BDNF se elevam de acordo com a instituição de tratamento para a patologia, expressando que, ao abordar a doença, as vias desse fator são positivamente afetadas. Dessa forma, alguns autores, sugerem que o BDNF pode ser um aliado no diagnóstico do transtorno depressivo, sendo que apresenta boa sensibilidade e especificidade, as quais ainda podem ser acuradas quando em associação com outros fatores ligados à doença.

Outrossim, ressalta-se que alterações genéticas e epigenéticas rastreáveis por análise genômica, ao afetarem a expressão do BDNF, se relacionam com a maior predisposição ao desenvolvimento de desequilíbrios do humor e até transtorno depressivo, o que pode indicar que existem marcadores de fatores de risco para o desenvolvimento de tais doenças, consoantes aos genes que expressam o BDNF.

Além disso, diversos autores sugerem o uso de técnicas que aumentam o BDNF, como adjuvância aos tratamentos convencionais para o transtorno depressivo, de forma que se destacam a prática de exercícios aeróbios que estimulam a neurogênese e a neuroplasticidade, assim como técnicas de gasto de energia e movimentos corporais gerados pelos músculos esqueléticos, denominada PA e, por fim, a restrição calórica como fator protetor para os tecidos neuronais.

Entretanto, nem tudo ainda está bem estabelecido em relação ao BDNF, inclusive, existem estudos que, apesar de 
reconhecerem os níveis alterados do mesmo em consonância com o transtorno depressivo, não encontraram resultados robustos o suficiente para afirmar que o BDNF poderia ser usado como um dos principais marcadores para a doença, limitando essa posição apenas quando a depressão está relacionada com ideação suicida, esquizofrenia ou, ainda, o transtorno bipolar.

Por fim, e baseado nas informações sumarizadas acima, fica evidente que há um caminho promissor a ser percorrido, tendo o BDNF e suas associações com o transtorno depressivo como alvo. No entanto, novos estudos precisam ser realizados, com maior abrangência quanto à quantidade de amostras e mais esclarecedores no que tange aos valores séricos desse fator, a serem considerados como corte para o diagnóstico ou predição da depressão. Assim, o uso de tal marcador poderá ser acoplado à rotina de hospitais e instituições de saúde e ficará à disposição da população no auxílio de suas necessidades.

Como sugestão aos trabalhos futuros que abordarem a mesma temática, fica o fato de que, quanto mais abrangentes são as amostras pesquisadas, mais se obterá um resultado fidedigno, bem como quanto mais semelhantes forem os grupos estudados, melhor acurado será o resultado. Um caminho relevante a ser explorado, será a pesquisa dos valores de corte, para definir os níveis de BDNF que podem ser considerados como preditores de transtorno depressivo. Ademais, poderá haver foco nos estudos que demonstram quais os benefícios de técnicas que englobem a mudança de estilo de vida, a fim de restaurar os níveis de BDNF e prevenir ou mesmo tratar os transtornos neuropsicológicos e, finalmente, trabalhos que demonstrem definidamente quais as consequências que a superexpressão do BDNF pode gerar ao organismo a longo prazo, são essenciais para estabelecer técnicas e tratamentos que atuam elevando o mesmo.

\section{Agradecimentos}

Expressamos nossos sinceros agradecimentos à Sra. Prof. ${ }^{a}$ Alejandra Bagnoli, por sua gentil cooperação com este trabalho, auxiliando na correção dos termos aqui contidos em língua espanhola, e também a Sra. Vanderleia Mello, por sua prestatividade em nos contactar com a Prof. ${ }^{\text {a }}$ Alejandra Bagnoli.

\section{Referências}

Ai, M., Wang, J., Chen, J., Wang, W., Xu, X., Gan, Y., Li, X., Gou, X., Cao, J., Lv, Z., Chen, X., Wang, H., Ma, Q., \& Kuang, L. (2019). Plasma brain-derived neurotrophic factor (BDNF) concentration and the BDNF Val66Met polymorphism in suicide: a prospective study in patients with depressive disorder. Pharmacogenomics and personalized medicine. (12). 97-106. https://doi.org/10.2147/PGPM.S201187

Aldoghachi, A. F., Tor, Y. S., Redzun, S. Z., Lokman, K. A. B., Razaq, N. A. A., Shahbudin, A. F., Badamasi, I. M., Cheah, P-S., Stanslas, J., Veerakumarasivam, A., Rosli, R., Ibrahim, N., Lye, M. S., \& Ling, K-H. (2019). Screening of brain-derived neurotrophic factor (BDNF) single nucleotide polymorphisms and plasma BDNF levels among Malaysian major depressive disorder patients. PLoS ONE. 14(1). e0211241. https://doi.org/10.1371/journal. pone.0211241.

Arosio, B., Guerini, F. R., Voshaar, R. C., \& Aprahamian, I. (2021). Blood Brain-Derived Neurotrophic Factor (BDNF) and Major Depression: Do We Have a Translational Perspective? Front Behav Neurosci. 626906(15) 10.3389/fnbeh.2021.626906

Associação Psiquiátrica Americana. (2014). Manual Diagnóstico e Estatístico de Transtornos Mentais (5a ed.). American Psychiatric Publishing

Bassi, S., Costa, L., Lesik, L., Faccioli, J., Finkelsztein, C., \& Cajal, A. (2018). Interaction between polymorphisms in SLC6A4 and BDNF on major depressive disorder in a sample of the argentinean population. Rev. Hosp. Ital. 38(1), 5-10.

Capibaribe, V. C. C. (2018). Potencial antidepressivo do timol: efeitos sobre os níveis do fator neurotrófico derivado do cérebro (BDNF) no modelo de estresse crônico induzido por corticosterona em camundongos. Dissertação de mestrado. Universidade Federal do Ceará (UFC), Fortaleza, CE, Brasil.

Chiou, Y. J., \& Huang, T. L. (2017). Serum Brain-Derived Neurotrophic Factors in Taiwanese Patients with Drug-Naïve First-Episode Major Depressive Disorder: Effects of Antidepressants. International Journal of Neuropsychopharmacology. 20(3). 213-218. 10.1093/ijnp/pyw096

Chiou, Y. J., \& Huang, T. L. (2019). Accuracy of brain-derived neurotrophic factor levels for differentiating between Taiwanese patients with major depressive disorder or schizophrenia and healthy controls. PLOS ONE. 14(2): e0212373. https://doi.org/10.1371/journal.pone.0212373

Colaço, C. S. (2018). Avaliação do potencial antidepressivo da ayahuasca em ratos: comportamento, quantificação de monoaminas e do fator neurotrófico derivado do cérebro $(B D N F)$. Dissertação de mestrado, Universidade de Brasília (UnB), Brasília, DF, Brasil.

Colucci-D’Amato, L., Speranza, L., \& Volpicelli, F. (2020). Neurotrophic factor BDNF, physiological functions and therapeutic potential in depression, neurodegeneration and brain cancer. Int. J. Mol. Sci. 21(7777). https://doi.org/10.3390/ijms21207777.

Diniz, D. M., Calabrese, F., Brivio, P., Riva, M. A., Grandjean, J., \& Homberg, J. R. (2021). BDNF overexpression in the ventral hippocampus promotes antidepressant- and anxiolytic-like activity in serotonin transporter knockout rats. Int. J. Mol. Sci. 22(5040). https://doi.org/10.3390/ijms22095040. 
Emon, P. Z., Das, R., Nishuty, N. L., Qusar, M. M. A. S., Bhuiyan, M. A., \& Islam, R. (2020). Reduced serum BDNF levels are associated with the increased risk for developing MDD: a case-control study with or without antidepressant therapy. BMC Res Notes. 13(83). https://doi.org/10.1186/s13104-020-04952-3.

Ferrer, A., Labad, J., Salvat-Pujo, N., Barrachina, M., Costas, J., Urretavizcaya, M., Arriba-Arnau, A., Crespo, J. M., Soriano-Mas, C., Carracedo, Á., Menchón, J. M., \& Soria, V. (2019). BDNF genetic variants and methylation: effects on cognition in major depressive disorder. Translational Psychiatry. 9(265). https://doi.org/10.1038/s41398-019-0601-8.

Galvão, T. F., Pansan, T., \& Harrad, D. (2015). Principais itens para relatar Revisões sistemáticas e Meta-análises: A recomendação PRISMA. Epidemiol. Serv. Saúde. 24 (2)

Gökçe, E., Güneş, E., \& Nalçaci, E. (2019). Effect of exercise on major depressive disorder and schizophrenia: a BDNF focused approach. Arch Neuropsychiatry. 2019(56). 302-310. https://doi.org/10.29399/npa.23369.

Guerra, T. R. B., \& Mesquita, E. T. (2020). Visão metabolômica envolvendo depressão e insuficiência cardíaca: uma análise reflexiva. Research, Society and Development. 9(8). e455986035. http://dx.doi.org/10.33448/rsd-v9i8.6035.

Guerrera, C.S., Furneri, G., Grasso, M., Caruso, G., Castellano, S., Drago, F., Di Nuovo, S., \& Caraci, F. (2020). Antidepressant Drugs and Physical Activity: A Possible Synergism in the Treatment of Major Depression? Front. Psychol. 857(11). https://doi.org/10.3389/fpsyg.2020.00857

Khan, M. S., Wu, G. W. Y., Reus, V. I., Hough C. M. Lindqvist, D., Westrinc, A., Nier, B. M., Wolkowitz, O. M., \& Mellond, S. H. (2019). Low serum brainderived neurotrophic factor is associated with suicidal ideation in major depressive disorder. Psychiatry Research. 273. 108-113. https://doi.org/10.1016/j.psychres.2019.01.013

Kishi, T., Yoshimura, R., Ikuta, T., \& Iwata, N. (2018). Brain-Derived Neurotrophic Factor and Major Depressive Disorder: Evidence from Meta-Analyses. Frontiers in Psychiatry. 8 (308). 10.3389/fpsyt.2017.00308

Kurdi, F. N., \& Flora, R. (2019). Physical Exercise Increased Brain-Derived Neurotrophic Factor in Elderly Population with Depression. Open access Macedonian journal of medical sciences. 13(7). 2057-2061. https://doi.org/10.3889/oamjms.2019.574

Lin, C-C., \& Huang, T-L. (2020). Brain-derived neurotrophic factor and mental disorders. biomedical journal. 43. 134-142. https://doi.org/10.1016/j.bj.2020.01.001.

Mizoguchi, Y., Yao, H., Imamura, Y., Hashimoto, M., \& Monji, A. (2020). Lower brain-derived neurotrophic factor levels are associated with age-related memory impairment in community-dwelling older adults: the Sefuri study. Nature Scientific Reports. 10 (16442). https://doi.org/10.1038/s41598-020-73576-1

Oh, H., Piantadosi, S. C., Rocco, B. R., Lewis, D. A., Watkins, S. C., \& Sibille, E. (2019). The Role of Dendritic Brain-Derived Neurotrophic Factor Transcripts on Altered Inhibitory Circuitry in Depression. Biological psychiatry, 85(6), 517-526. https://doi.org/10.1016/j.biopsych.2018.09.026

Park, Y. M., \& Lee, B. H. (2018). Alterations in Serum BDNF and GDNF Levels after 12 Weeks of Antidepressant Treatment in Female Outpatients with Major Depressive Disorder. Psychiatry investigation. 8(15). p.818-823. https://doi.org/10.30773/pi.2018.03.31

Pastori, T. A. N. (2020). Depressão: uma epidemia? Dissertação de mestrado. Fundação Oswaldo Cruz (Escola Nacional de Saúde Pública Sergio Arouca), Rio de Janeiro, RJ, Brasil.

Perito, M. E. S., \& Fortunato, J. J. (2012). Marcadores biológicos da depressão: uma revisão sobre a expressão de fatores neurotróficos. Rev Neurocienc. 20(4). $597-603$.

Phillips, C. (2017). Brain-derived neurotrophic factor, depression, and physical activity: making the neuroplastic connection. Neural Plasticity. 2017(7260130). 17. https://doi.org/10.1155/2017/7260130.

Rafa-Zablocka, K., kreiner, G., baginska, M., \& Nalepa, I. (2018). Selective Depletion of CREB in Serotonergic Neurons Affects the Upregulation of BrainDerived Neurotrophic Factor Evoked by Chronic Fluoxetine Treatment. Frontiers in Neuroscience. 12 (637). https://doi.org/10.3389/fnins.2018.00637

Ritter, O. M. S., Allonço, M., \& Lima, F. (2021). Content analysis as a methodology in Qualis-CAPES A1 journals in Science Education. Research, Society and Development. Research Society and Development. 10(3), e43110313378

Rossetti, A. C., Paladini, M. S., Trepci, A., Mallien, A., Riva, M. A., Gass, P., \& Molteni, R. (2019). Differential Neuroinflammatory Response in Male and Female Mice: A Role for BDNF. Frontiers in Molecular Neuroscience. 12 (166). 10.3389/fnmol.2019.00166

Sartori, C. R. (2010). Efeito antidepressivo e cognitivo da atividade física associado a alterações pós-traducionais do Fator Neurotrófico Derivado do Cérebro $(B D N F)$. Tese de doutorado, Universidade Estadual de Campinas (UNICAMP), Campinas, SP, Brasil.

Shan, D., Zheng, Y. D., \& Froud, K. (2021). Brain-derived neurotrophic factor as a clinical biomarker in predicting the development of post-stroke depression: a review of evidence. Cureus. 13(6). p. e15662. https://doi.org/10.7759/cureus.15662.

Syafrita, Y., Amir, D., Susanti, R., \& Fadhilah, I. (2020). Relationship of brain-derived neurotrophic factor, malondialdehyde, and 8-Hydroxy 2-Deoxyguanosine with post-ischemic stroke depression. Dement Neuropsychol. 14(1) p. 41-46. http://dx.doi.org/10.1590/1980-57642020dn14-010007.

Teng, Z., Wang, L., Li, S., Tan, Y., Qiu, Y., Wu, C., Jin, K., Chen, J., Huang, J., Tang, H., Xiang, H., Wang, B., Yuan, H., \& Wu, H. (2021). Low BDNF levels in serum are associated with cognitive impairments in medication-naïve patients with current depressive episode in BD II and MDD. Journal of Affective Disorders. 293. 90-9. https://doi.org/10.1016/j.jad.2021.06.018

Troyan, A. S., \& Levada, O. A. (2020). The diagnostic value of the combination of serum brain-derived neurotrophic factor and insulin-like growth factor-1 for major depressive disorder diagnosis and treatment efficacy. Front. Psychiatry. 11(800). https://doi.org/10.3389/fpsyt.2020.00800. 
Research, Society and Development, v. 10, n. 10, e461101019139, 2021

(CC BY 4.0) | ISSN 2525-3409 | DOI: http://dx.doi.org/10.33448/rsd-v10i10.19139

World Health Organization - WHO. (2017). Depression and other common mental disorders. Global health estimates. Documento técnico. World Health Organization, Genebra, Suíça.

Xu, W., Yao, X., Zhao, F., Zhao, H., Cheng, Z., Yang, W., Cui, R., Xu, S., \& Li, B. (2020). Changes in hippocampal plasticity in depression and therapeutic approaches influencing these changes. Neural Plasticity. 2020(8861903). 16. https://doi.org/10.1155/2020/8861903.

Yang, T., Nie, Z., Shu, H., Kuang, Y., Chen, X., Cheng, J., Yu, S., \& Liu H. (2020). The Role of BDNF on Neural Plasticity in Depression. Front Cell Neurosci. 82(14). 10.3389/fncel.2020.00082.

Youssef, M. M., Underwood, M. D., Huang, Y-Y., Hsiung, S-c., Liu, Y., Simpson, N. R., Bakalian, M. J., Rosoklija, G. B., Dwork, A. J., Arango, V., \& Mann, J. J. (2018). Association of BDNF Val66Met polymorphism and brain BDNF levels with major depression and suicide. International Journal of Neuropsychopharmacology. 21(6). 528-538. https://doi.org/10.1093/ijnp/pyy008.

Zheng, W., Zhou, Y. L., Wang, C. Y., Lan, X. F., Zhang, B., Zhou, S. M., Yan, S., \& Ning, Y. P. (2021). Plasma BDNF concentrations and the antidepressant effects of six ketamine infusions in unipolar and bipolar depression. PeerJ. 10989 (9). https://doi.org/10.7717/peerj.10989

Zhong, F., Liu, L., Wei, J. L., Hu, Z. L., Li, L., Wang, S., Xu, J. M., Zhou, X. F., Li, C. Q., Yang, Z. Y., \& Dai, R. P. (2019). Brain-Derived Neurotrophic Factor Precursor in the Hippocampus Regulates Both Depressive and Anxiety-Like Behaviors in Rats. Front. Psychiatry. 9 (776). 10.3389/fpsyt.2018.00776

Zhou, C., Zhong, J., Zou, B., Fang, L., Chen, J., Deng, X., Zhang, L., Zhao, X., Qu, Z., Lei, Y., \& Lei, T. (2017). Meta-analyses of comparative efficacy of antidepressant medications on peripheral BDNF concentration in patients with depression. PLoS ONE. 12(2): e0172270. 10.1371/journal.pone.0172270 